\title{
Estudo bibliométrico da produção científica dos docentes do Depar- tamento de Física da UFMG entre 2012 e 2016
}

\author{
Bibliometric study of the scientific production of the professors of the Physics Department \\ of UFMG between 2012 and 2016
}

Carlos Basílio Pinheiro

Doutor em Física

Universidade Federal de Minas Gerais

cbpinheiro@ufmg.br

Gabriela Silva Caetano

Graduação em Biblioteconomia

Universidade Federal de Minas Gerais

gbriela.caetano@gmail.com

\author{
Bruno Fernandes Magalhães de Oliveira \\ Graduação em Biblioteconomia \\ Universidade Federal de Minas Gerais \\ bfmoliveira@gmail.com
}

\section{Resumo}

Estudo bibliométrico de caráter descritivo aplicado à produção científica do Departamento de Física do Instituto de Ciências Exatas (ICEx) da Universidade Federal de Minas Gerais (UFMG), de acordo com as seguintes unidades de análise: autores, publicações, periódicos de publicação (e seus indicadores de impacto), citações, colaboração, tempo de UFMG dos docentes e de obtenção de doutorado, dentre outras. Os dados, cobrindo os anos 2012 a 2016, foram coletados na base de dados Scopus e nas plataformas Somos UFMG, Lattes e SCImago Journal \& Country Rank (SJR). Buscou-se responder a seguinte pergunta: quais das unidades de análise, e em quais situações, parecem interferir mais fortemente na produção científica em termos de quantidade de artigos produzidos e citações recebidas? As análises empreendidas sugeriram, entre outros: queda consistente da produção nos anos investigados, concentração da produção em grupo pequeno de docentes, correlação entre idade/tempo de doutorado e produtividade; correlação inversa entre produtividade e número total de citações, e correlação inversa entre produtividade e tempo de permanência na UFMG.

\section{Palavras-chave}

Bibliometria. Produção Científica. Física. Instituto de Ciências Exatas. Universidade Federal de Minas Gerais.

\section{Abstract}

It is a descriptive bibliometric research applied to the scientific production in the Department of Physics of the Institute of Exact Sciences (Instituto de Ciências Exatas, ICEx), in the Universidade Federal de Minas Gerais (UFMG), in accordance to the following analysis units: authors, publications, periodical publications (and their impact indicators), citations, collaboration, time teaching in the University and time of doctorate graduation, among others. The data, ranging from 2012 to 2016, was collected in the Scopus database, and in the platforms Somos UFMG, Lattes and the SCImago Journal \& Country 
Rank (SJR). The following question was sought to be answered: Which of the units, and in which situations, seem to interfere the most in scientific production, in terms of quantity of articles produced and citations received? The analyses employed suggested a consistent decrease in production in the years investigated, concentration of production in a small group of academics, correlation between age, PhD degree time and productivity; inverse correlation between productivity and number of cumulative citations, and inverse correlation between productivity and professional engagement time at the University.

\section{Keywords}

Bibliometrics. Scientific Production. Physics. Instituto de Ciências Exatas. Universidade Federal de Minas Gerais.

\section{INTRODUÇÃO}

A bibliometria é um conjunto de métodos e técnicas quantitativas e estatísticas que propicia mensurar a produção científica de um determinado escopo, seja ele um grupo de pesquisa, um departamento, uma instituição ou um país. No âmbito da comunicação científica, toma por unidades de análise artigos, citações, coautoria, periódicos, ano de publicação, dentre outras, das quais emergem insigths reveladores sobre as características da produção científica que esteja sob enfoque. Estas unidades podem ainda ser cruzadas com outras informações não propriamente bibliométricas, a exemplo da idade dos pesquisadores ou seus locais de formação acadêmica, para ampliar a compreensão sobre o comportamento da produção científica identificado na análise. Ocorre que tais cruzamentos permitem afastar a pesquisa da frieza comum dos estudos exclusivamente quantitativos, uma vez que atribuem significados qualitativos aos dados. Tanto assim que, ainda mais profundamente, Araújo (2006, p. 25) identifica na evolução da bibliometria estudos que aliam às técnicas bibliométricas outros métodos e referenciais teóricos, de modo "[...] que se utilizam de dados bibliométricos mas que realizam uma leitura desses dados à luz de elementos do contexto sócio-histórico em que a atividade científica é produzida."

Desta maneira, a bibliometria constitui-se como valioso instrumento tanto para compreender a atividade científica em si quanto para fornecer subsídios aos gestores responsáveis por políticas de fomento à pesquisa. Nas palavras de Bordons e Zulueta (1999, p. 790),

Los estudios bibliométricos tienen por objeto el tratamiento y análisis cuantitativo de las publicaciones científicas. Forman parte de los "estudios sociales de la ciencia" y entre sus principales aplicaciones se encuentra el área de la política científica. Estos estudios complementan de manera eficaz las opiniones y los juicios emitidos por los expertos de cada área proporcionando herramientas útiles y objetivas en los procesos de evaluación de los resultados de la actividad científica.

Ao apresentar o pensamento de Derek de Solla Price, Braga (1974, p. 168) afirma que seus estudos "[...] têm importância capital para os que procuram compreender, medir e avaliar a extensão e força do impacto da Ciência e da Tecnologia sobre nossa Sociedade." E, dessa forma, ilustra o potencial da bibliometria com a seguinte afirmação:

Empregando métodos estatísticos, Solla Price quantifica autores, documentos, recursos humanos, citações bibliográficas etc. e através dessas análises quantitativas procura descobrir a lógica interna da Ciência e da Tecnologia, os princípios que as governam e as regras necessárias para lidar com elas. (BRAGA, 1974, p. 168). 
A bibliometria nasceu das necessidades profissionais de bibliotecários, por exemplo, para quantificação de edições e exemplares de livros, mas desde o início do século passado foi sendo direcionada para avaliação da produção científica "[...] como sintoma da necessidade do estudo e da avaliação das atividades de produção e comunicação científica." (ARAÚJO, 2006, p. 12). E se no início do século XX a atividade científica já demandava compreensão, "Nas últimas décadas, acompanhando a expansão da ciência e da tecnologia, tornou-se cada vez mais evidente a necessidade de avaliar tais avanços [...]" (VANTI, 2002, p. 152).

No Brasil, Lima (1993, p. 236) identifica na década de 1970 o início das investigações sobre a produção científica, tendo como objeto de estudo as instituições de ensino e de pesquisa - universidades e institutos. A autora realizou um apanhado dos estudos sobre produção científica em geral, mas com ênfase na área da agricultura, analisando dezoito trabaIhos publicados até aquele ano. Em sua síntese, observou que "A produção científica é abordada sob vários aspectos, predominando os estudos que consideram o perfil dos autores mais produtivos, ou seja, faixa etária, formação acadêmica, experiência profissional, domínio de idiomas estrangeiros, entre outros [...]" concluindo que "Pode-se pressupor que há algum tipo de relação entre a produção científica e a idade, a qualificação acadêmica e a experiência de cada indivíduo." (LIMA, 1993, p. 236).

Estudos de mesmo viés foram realizados depois do levantamento de Lima (1993). Por exemplo, a produção científica dos 17 docentes do Departamento de Biblioteconomia e Documentação da Universidade Federal da Paraíba, no período de 1996 a 2000, foi analisada por Leite e Ramalho (2005). Os autores também traçaram o perfil destes docentes em termos de sexo, idade, enquadramento funcional e tempo de instituição, mas sem correlacionar estes dados e a produção científica analisada.

Já Medeiros e Faria (2006, p. 14) consideraram que havia poucos estudos detalhados sobre a produção científica das universidades públicas paulistas de destaque e, então, aplicaram análise bibliométrica sobre a produção científica da Universidade Estadual Paulista Júlio de Mesquita Filho (Unesp) no período de 2000 a 2004 disponível na base de dados Web of Science. $O$ estudo dos autores "[...] possibilitou identificar a sua evolução e seu crescimento anual, as áreas em que mais se publicam, as cidades e os países que mais colaboram, além de uma análise de seus institutos." (MEDEIROS; FARIA, 2006, p. 14).

Por sua vez, indicadores bibliométricos de atividade de impacto e de coautoria foram utilizados por Brambilla e Stumpf $(2012$, p.36) para analisar uma década de artigos publicados em periódicos indexados na Web of Science por autores da Universidade Federal do Rio Grande do Sul (UFRGS). O estudo foi de caráter descritivo, uma vez que apresentou como resultado a evolução no tempo da quantidade de artigos desta universidade recuperados na base e sua taxa média de crescimento, o idioma em que foram publicados, as áreas do conhecimento com maiores quantidades de citações recebidas e o padrão, em número de autores, de coautoria dos artigos.

A fim de diagnosticar fatores intervenientes na produção científica dos docentes dos programas de pós-graduação na área da Física de três universidades federais brasileiras, Correia, Alvarenga e Garcia (2014) separaram o trabalho desses profissionais em cinco grupos, a saber: Grupo 1 - Atividade acadêmica; Grupo 2 - Produção científica, técnica, artística e cultural; Grupo 3 - Extensão; Grupo 4 - Formação e capacitação - desconsiderado na análise; e Grupo 5 - Atividade de administração. As autoras analisaram o período entre 2007 e 2009, aplicando métodos de natureza quantitativa - bibliometria e cientometria - e qualitativa análise de conteúdo. Chegaram à conclusão de que a maioria dos docentes dedicou-se no período às atividades dos Grupos 1, 2 e 3, mas que apenas 1\% deles se dedicou às atividades 
do Grupo 5, embora estas não tenham interferido "[...] negativamente em outras atividades, sequer na produção científica dos docentes." (CORREIA; ALVARENGA; GARCIA, 2014, p.116).

Mueller (2013) realizou levantamento dos estudos métricos, publicados em 2011 e 2012, realizados sobre a unidade de análise artigo de periódico. A autora identificou 54 destes trabalhos concluindo que eles "[...] privilegiaram estudos aplicados, voltados principalmente para a descrição de produção de documentos em áreas específicas e descrição de características dessas literaturas." (MUELLER, 2013, p. 19).

Identificamos um estudo que se debruçou sobre a produção científica de departamentos da Universidade Federal de Minas Gerais (UFMG). Guirado (2015), em seu mestrado, analisou as características gerais da produção científica de três departamentos do Instituto de Ciências Biológicas da UFMG indexada nas bases de dados Web of Science e SCOPUS. Suas conclusões versaram sobre pesquisadores mais produtivos, número de autores por artigo, rede colaborativa, fator de impacto, Qualis CAPES e áreas temáticas dos títulos dos periódicos onde os trabalhos foram publicados, idioma de publicação, documentos mais citados e evolução da produção nos anos analisados.

Este trabalho se insere na série de estudos relatados acima. Nesse sentido, configurase como um estudo bibliométrico de caráter descritivo aplicado à produção científica do Departamento de Física do Instituto de Ciências Exatas (ICEx) da UFMG, entre os anos de 2012 a 2016, de acordo com as seguintes unidades de análise: autores, publicações, periódicos de publicação - e seus indicadores de impacto -, citações, coautoria, tempo de UFMG e tempo e local - país e instituição - de doutorado.

Considerando as unidades de análise, a pergunta geral que se faz é: quais delas, e em quais situações, parecem interferir mais fortemente na produção científica em termos de quantidade de artigos produzidos e citações recebidas por estes trabalhos?

Embora nem a quantidade produzida nem o número de citações recebidas por artigos científicos sejam medidas precisas ou mesmo suficientes para aferir a qualidade destes e, além do mais, quantidade e qualidade sejam medidas diferentes, Braga (1974, p. 165), analisando a obra e proposições de Solla Price, esclarece que "[...] há uma grande correlação entre quantidade e qualidade, provocada pelo Matthew Effect ${ }^{1}$ : o sucesso qualitativo de um documento provoca subsequentes publicações de outros documentos; a ausência de sucesso tende a provocar o término da produtividade."

Nestes termos, os estudos de citações partem da premissa de que o número de vezes que um autor é citado na literatura indica seu prestígio dentro de uma determinada comunidade. Assim, os estudos de citações

[...] nos permitem mapear um campo emergente ou consolidado, identificar seus principais atores e as relações que se estabelecem entre eles e identificar uma série de características do comportamento de uso da informação recuperada. Assim, os estudos de citação constituem um importante indicador da atividade científica, pois contribuem para entender a estrutura e o desenvolvimento da ciência e também identificam as regularidades de seu funcionamento. (VANZ; CAREGNATO, 2003, p. 255).

\footnotetext{
${ }^{1}$ O Matthew Effect foi postulado pelo sociólogo Robert K. Merton inspirado no Evangelho de Mateus: "Pois a quem tem, mais será dado, e terá em grande quantidade. Mas a quem não tem, até o que tem lhe será tirado." (Mateus, 25:29). Solla Price observou o mesmo fenômeno ao estudar a rede de citações entre documentos científicos, mas usou a expressão "vantagem cumulativa" para designá-lo (PERC, 2014).
} 
Além do que foi exposto quanto à utilidade dos estudos métricos, é preciso considerar um fator crucial que impõe sua necessidade: é o caráter exponencial do crescimento do volume de trabalhos científicos publicados, conforme apontado por Solla Price (BRAGA, 1974). Esse crescimento pode ser observado tanto em relação à produção científica mundial, quanto em relação a um país ou mesmo uma instituição. A Gráfico 1 apresenta o crescimento da produção de artigos científicos publicados por docentes da UFMG entre 1980 e 2017.

Gráfico 1 - Quantidade de artigos produzidos por docentes da UFMG - 1980 a 2017

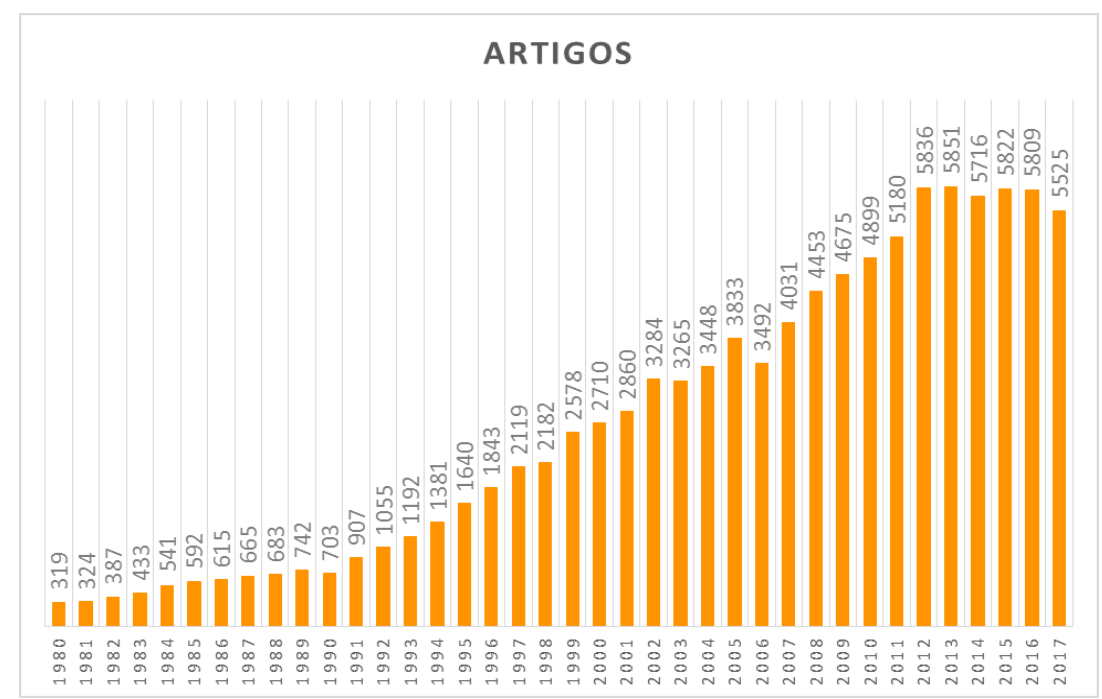

Fonte: Somos UFMG (2017).

Esta mesma produção dividida pelas unidades acadêmicas da UFMG, conforme Gráfico 2, mostra que o ICEx representa a terceira com maior concentração de publicações. Dos cinco departamentos do Instituto, cerca de $36 \%$ são de docentes do Departamento de Física.

Gráfico 2 - Artigos por Unidade Acadêmica da UFMG

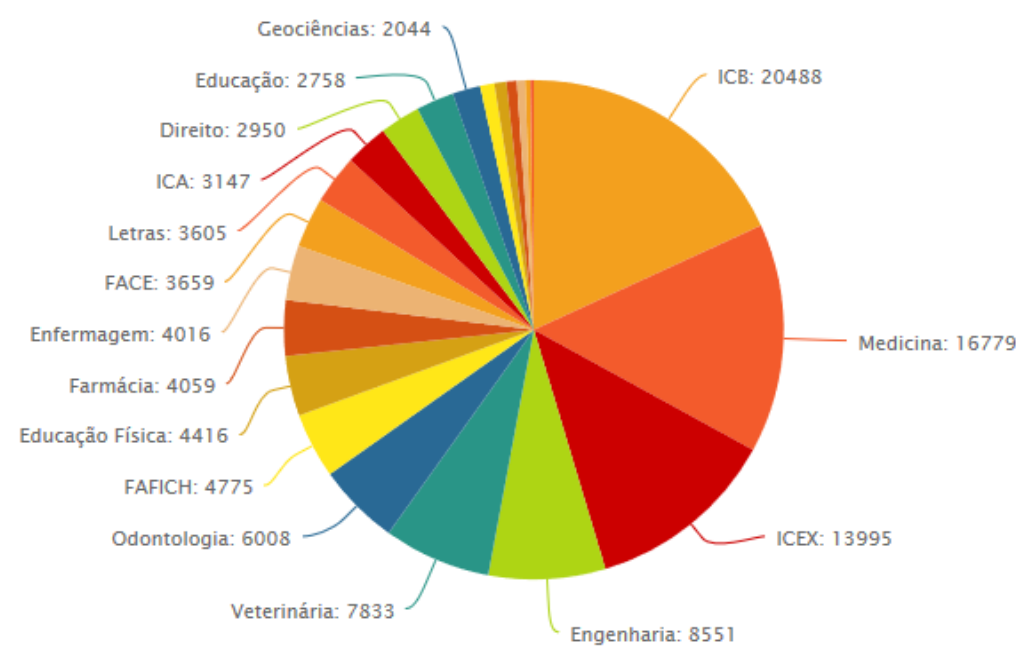

Fonte: Somos UFMG (2017).

Além desta introdução, na seção 2 é apresentada a metodologia utilizada nesse trabalho, na terceira a caracterização do Departamento de Física, na quarta a análise da produ- 
ção científica do período considerado para, finalmente, tratarmos das conclusões desse estudo.

\section{METODOLOGIA}

A pesquisa foi realizada a partir dos dados disponíveis nas plataformas SOMOS $^{2}$ (UFMG), Lattes ${ }^{3}$ (CNPq), Google Scholar ${ }^{4}$ e na base SCOPUS ${ }^{5}$ (Elsevier). O período escolhido para a análise foi compreendido entre os anos de 2012 a 2016, tendo como base o ano de 2017.

A produção científica considerada neste estudo levou em conta os docentes do quadro ativo permanente do Departamento de Física do ICEx da UFMG, uma vez que, em tese, esses são profissionais em pleno exercício de suas atividades de ensino, pesquisa e extensão. Dos 73 vinculados ao Departamento, cinco foram desconsiderados dessa análise por não apresentarem dados na plataforma Somos UFMG e/ou Currículo Lattes ${ }^{6}$. Desse modo, o universo de análise limitou-se a 68 docentes.

Identificados os docentes, buscamos cada um na plataforma SOMOS da UFMG e copiamos da categoria "Artigos publicados" todos os artigos relativos aos anos de 2012 a 2016, o que alcançou 983 títulos correspondentes a 736 documentos individuais - há artigos escritos por dois ou mais professores do Departamento. Como esta plataforma não apresenta informações além da produção dos autores - não apresenta os eventuais coautores -, títulos dos artigos e ano de publicação, foi necessário recorrer a outras fontes para obtermos dados relativos às demais unidades de análise.

Assim, na base de dados SCOPUS, escolhida por apresentar cobertura mais abrangente de documentos com autores afiliados à UFMG, buscamos informações quanto à quantidade de citações, informações relativas aos documentos citantes e periódicos de publicação. Em relação a estes, extraímos da plataforma SCImago Journal \& Country Rank (SJR) informações acerca do impacto dos periódicos, bem como suas categorias de classificação na base ${ }^{7}$. Vale chamar a atenção para o fato de que nem todos os artigos estão publicados em periódicos indexados pela base e, consequentemente, nem todos os periódicos estão indexados na base.

Como primeira estratégia utilizada para recuperar informações relativas à produção dos 68 docentes do Departamento de Física, procuramos pela afiliação institucional utilizando a seguinte expressão de busca na opção Advanced da base na Scopus: AFFIL (UFMG) AND (AFFIL ("Department of Physics") OR AFFIL ("Departamento de Física")). Esta busca retornou 509 documentos. Obtivemos (pelo menos um) resultado de recuperação que considerou o operador booleano AND somando a afiliação institucional de dois autores diferentes. Para mitigar este tipo de erro, utilizamos os resultados da busca anterior para levantarmos as formas de escrita que os autores filiados ao Departamento de Física utilizam como afiliação institucional. Esta estratégia recuperou 2.927 documentos. Considerando o recorte temporal entre 2012 e 2016, chegou-se a 817 resultados. Ainda assim foi necessário limitar o campo afiliação institucional à UFMG, restando por fim 757 documentos. Destes, 531 (71\%) têm

\footnotetext{
${ }^{2}$ http://somos.ufmg.br/.

3 http://lattes.cnpq.br/.

4 https://scholar.google.com.br/.

5 https://www.scopus.com/.

6 Por exemplo, um não tem currículo Lattes (ao que tudo indica), outros dois não são localizados na plataforma Somos UFMG e outros dois apresentam problemas de preenchimento do currículo Lattes.

${ }^{7}$ As informações destas duas fontes foram extraídas em 25 de outubro de 2017.
}

Ci. Inf. Rev., Maceió, v. 6, n. 2, p. 16-33, maio/ago. 2019 
entre os autores pelo menos um professor do quadro permanente do Departamento de Física.

Já na plataforma Lattes, para cada professor, colhemos as informações relativas ao tempo de trabalho na UFMG, bem como o tempo e o local de titulação no doutorado. Também da plataforma Lattes, foi obtida a informação relativa à quantidade de autores em cada artigo.

Finalmente foi realizado um estudo de índice de citação no Google Scholar. A metodologia utilizada para este processo consistiu na pesquisa das informações de cada pesquisador individualmente na base a fim de obter os dados desejados.

\section{O DEPARTAMENTO DE FÍSICA DA UFMG: CARACTERIZAÇÃO}

A palavra "physis" vem do grego antigo e significa natureza, de modo que podemos considerá-la como uma ciência pura que estuda a natureza e seus fenômenos. De acordo com o site do ICEx ${ }^{8}$, em Minas Gerais, o estudo da Física

[...] iniciou-se em 1941, com a criação do curso de Física na Faculdade de Filosofia de Minas Gerais, uma escola particular que foi incorporada à Universidade de Minas Gerais, em 1947. A criação do Departamento de Física se deu em 1963, ainda como parte da Faculdade de Filosofia, seguida, em 1964, pela aprovação do Novo Estatuto da Universidade, que previa a fundação dos Institutos Centrais de Matemática, Física, Química, Biologia e Filosofia. Em 1968 foi criado o Instituto de Ciências Exatas (ICEx), englobando Física, Matemática e Química (ICEx, [19--]).

A pós-graduação inicia-se em 1966 com criação do curso de Mestrado na área de Física do Estado Sólido, mas credenciado dois anos depois. Já o doutorado começa em 1970, sendo credenciado depois de quatro anos. O Programa de Pós-Graduação em Física (PPGF) tem sido avaliado com nota máxima (7) pela Fundação CAPES do Ministério de Educação, significando que atingiu excelência internacional. Nessas cinco décadas do Programa, até outubro de 2017 foram 597 dissertações e 329 teses defendidas, cuja evolução no tempo é mostrada na Figura 3.

Gráfico 3 - Evolução do total de dissertações e teses defendidas no PPGF

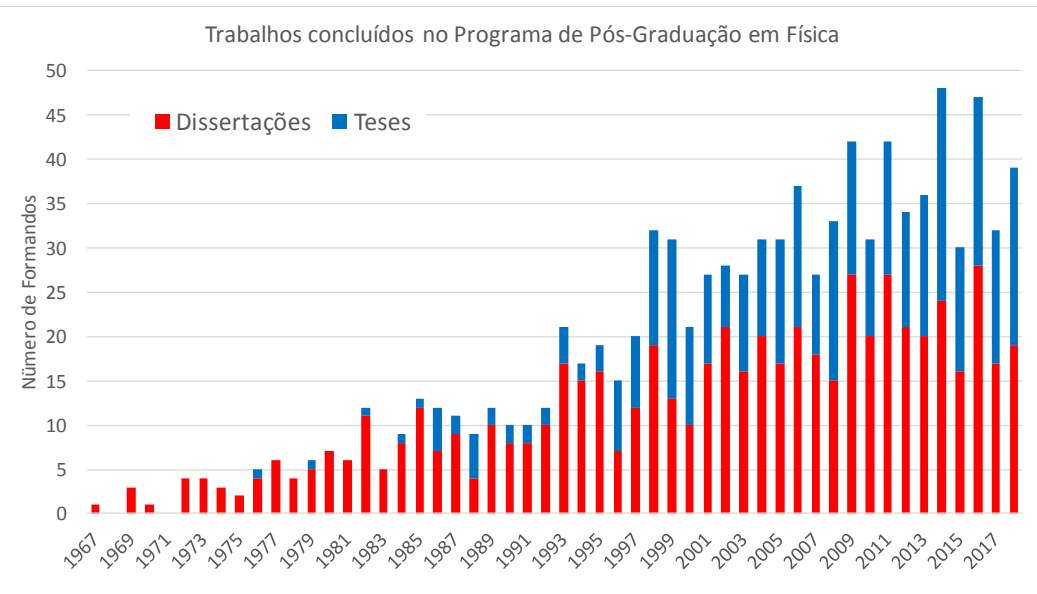

Fonte: Programa de Pós Graduação em Física $(2017)^{9}$.

${ }^{8}$ Disponível em: http://www.icex.ufmg.br/index.php/departamento-fisica. Acesso em: 07 nov. 2017. 
Além da consolidação do PPGF como um indicador de amadurecimento do Departamento como um todo, outro indicador é o fato de 11 professores do quadro permanente, com tempos superiores a 27 anos de trabalho no Departamento, terem obtido seu doutorado depois de já estarem no quadro permanente. Os 38 docentes contratados mais recentemente, com média aproximada de 15 anos no quadro permanente, entraram, no mínimo, no mesmo ano da titulação de doutor. Os pedidos de patente também evidenciam este amadurecimento. $O$ primeiro pedido realizado por um docente vinculado ao Departamento ocorreu há 15 anos e, nesse período, foram mais outros 51 pedidos - 18\% do total do ICEx.

$\mathrm{O}$ departamento conta 73 docentes do quadro permanente. Dentre os 68 em análise neste trabalho, 61 são do sexo masculino (M) e 7 do sexo feminino (F). Esses docentes podem ser classificados em três áreas de concentração de pesquisa (Física Experimental, Física Teórica e Astrofísica) conforme mostrado na Tabela 1.

Tabela 1 - Distribuição de docentes por sexo

\begin{tabular}{l|r|r|r}
\hline \multirow{2}{*}{\multicolumn{1}{c|}{ Área de concentração }} & \multicolumn{3}{c}{ Quantidade } \\
\cline { 2 - 4 } & Masculino & Feminino & f(\%) \\
\hline Física Experimental & 45 & 3 & $72 \%$ \\
\hline Física Teórica & 11 & 2 & $18 \%$ \\
\hline Astrofísica & 5 & 2 & $10 \%$ \\
\hline Total & 61 & 7 & $100 \%$ \\
\hline
\end{tabular}

Fonte: Elaboração própria a partir da Plataforma Lattes (CNPq, 2017).

Enquanto os homens têm em média 19,3 anos de UFMG e 21,7 de obtenção do título de doutor, os valores para as mulheres são, respectivamente, 11,9 e 19,3 anos. Em relação aos 68 docentes como um todo, o tempo médio de conclusão de doutorado é de 21,5 anos e de tempo que pertence ao quadro permanente da UFMG é de 18,6 anos. A dispersão desta última média nos indica que embora haja um grupo considerável de docentes (15\%) que trabalha na UFMG há pelo menos 37 anos, o maior grupo é formado por docentes ingressantes nos últimos seis anos. Ainda quanto ao tempo de permanência no quadro permanente da UFMG, das três áreas de concentração dos docentes do Departamento de Física, a com menor tempo médio de docência na Universidade é a Física Experimental, conforme Tabela 2.

Tabela 2 - Tempo médio de contratação na UFMG por área de concentração de Conhecimento

\begin{tabular}{c|c}
\hline Área de concentração & Tempo médio de UFMG \\
\hline Astrofísica & 20 \\
\hline Física Experimental & 17 \\
Física Teórica & 23 \\
\hline
\end{tabular}

Fonte: Elaboração própria a partir da Plataforma Lattes (CNPq, 2017).

Quando analisamos o país onde os docentes concluíram seu doutorado, pode-se observar através da Tabela 3 que 42 dos 68 professores foram formados no Brasil; desses, 32 obtiveram o doutorado pelo próprio PPGF e, portanto, 26 realizaram doutorado integralmente no exterior. Dessa forma observa-se uma endogenia de cerca de $47 \%$. Por fim, vale

${ }^{9}$ Disponível em: http://www.fisica.ufmg.br/posgrad/. Acesso em: 07 nov. 2017. 
dizer que os docentes apresentam grande presença no Google Scholar, tendo 50 deles (74\% do universo analisado) perfil cadastrado na ferramenta. Desses, o maior índice $\mathrm{H}$ é 77 e o menor é 6 .

Tabela 3 - País onde os docentes titularam-se como doutores

\begin{tabular}{l|c}
\hline País/Região & $f(\mathbf{x})$ \\
\hline Brasil (UFMG) & 32 \\
Brasil (outras instituições) & 10 \\
Europa (Alemanha, Dinamarca, Espanha, França, Holanda, Inglaterra e Suíça) & 20 \\
EUA & 6 \\
Total & 68 \\
\hline
\end{tabular}

Fonte: Elaboração própria a partir da Plataforma Lattes (CNPq, 2017).

\section{A PRODUÇÃO CIENTÍFICA DO DEPARTAMENTO DE FÍSICA DA UFMG}

O levantamento da produção científica do Departamento de Física entre 2012 e 2016 mostra que o tipo de produção predominante é o de artigos com 95\% do total, de maneira que as análises realizadas incluirão, de agora em diante, apenas essa tipologia de documento. No período analisado, a produção total foi de 736 artigos. Porém, alguns artigos foram escritos em colaboração e, para as análises subsequentes, eles serão contados mais de uma vez, ou seja, o mesmo artigo será contado uma vez para cada docente que participou de sua elaboração. Nestes termos, a produção total do Departamento de Física entre 2012 e 2016 foi de 983 artigos, mostrando-se declinante, como pode visualizado na Gráfico 4.

Gráfico 4 - Quantidade de artigos produzidos por ano

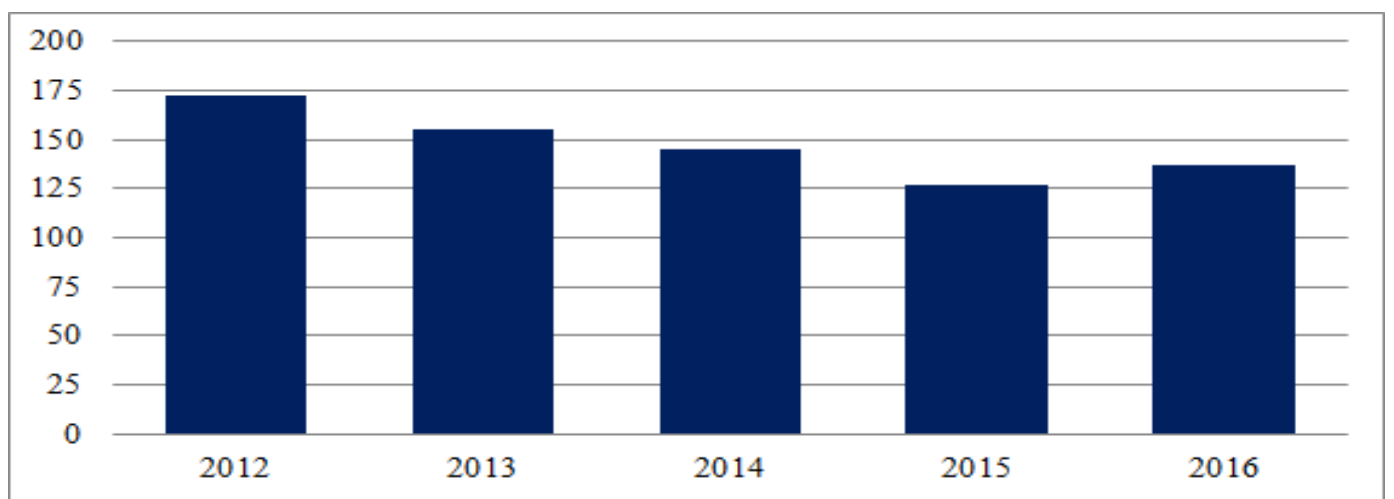

Fonte: Elaboração própria a partir de dados obtidos da plataforma Somos (UFMG, 2017).

A média de artigos produzida por docentes foi de 14,5 nos cinco anos analisados, portanto, média de quase 2,9 artigos por ano para cada docente. No entanto, essa média distorce certas conclusões, pois conforme mostrado no histograma do Gráfico 5, a quantidade de artigos produzidos por docentes decresce à medida que se eleva o número total de artigos produzidos por cada docente. Nota-se que aproximadamente dois terços dos docentes (42) produziram menos de dez artigos (média de pelo menos dois por ano) no período analisado e que apenas sete docentes produziram mais de 30 artigos (média de seis por ano). 
Gráfico 5 - Histograma da produção de artigos pelos docentes

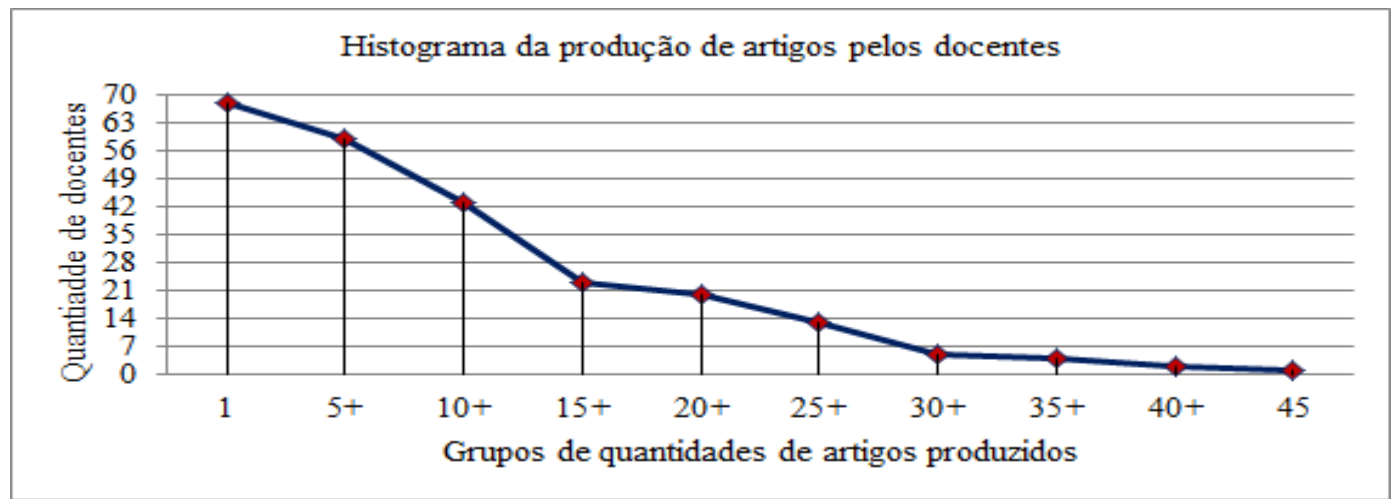

Fonte: Elaboração própria a partir de dados obtidos da plataforma Somos (UFMG, 2017).

Quando se analisa a frequência da produção científica por docente, agrupada no intervalo de cinco em cinco artigos, observa-se certa irregularidade na distribuição, conforme se aumenta o total de artigos (Gráfico 6).

Gráfico 6 - Frequência de artigos por professor

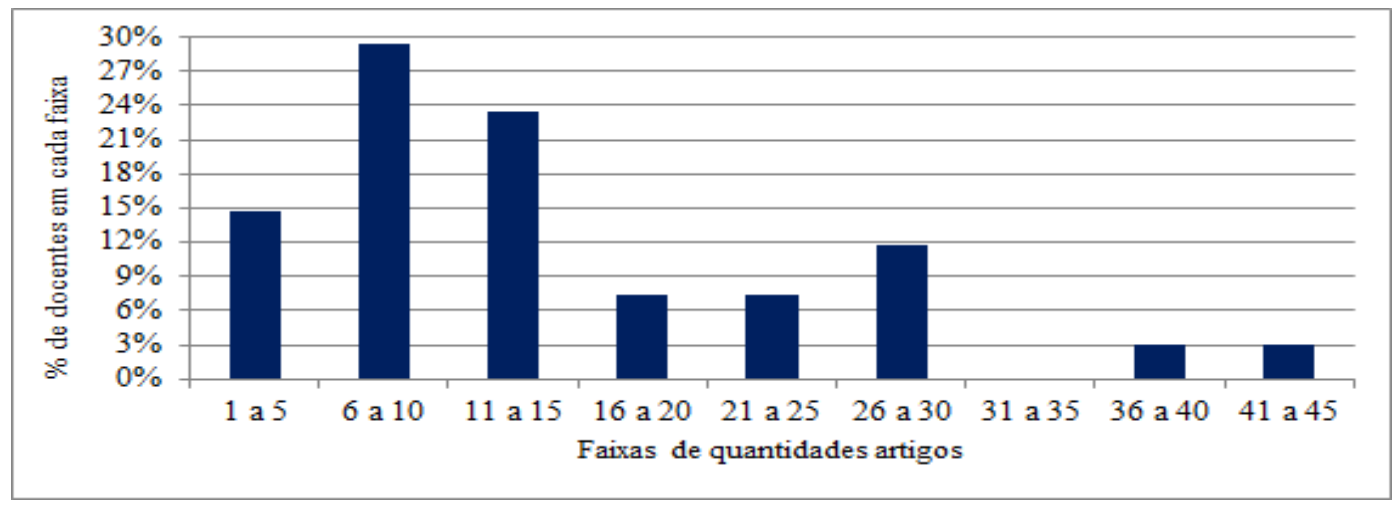

Fonte: Elaboração própria a partir de dados obtidos da plataforma Somos (UFMG, 2017).

Ao considerar o total médio de citações recebidas pelos artigos publicados nas três áreas de concentração do Departamento de Física, encontramos os resultados mostrados na Tabela 4.

Tabela 4 - Citações por área de concentração do conhecimento

\begin{tabular}{l|c|c|c}
\hline Área de concentração & $\begin{array}{c}\text { Quantidade de } \\
\text { docentes }\end{array}$ & $\begin{array}{c}\text { Média de } \\
\text { citações }\end{array}$ & $\begin{array}{c}\text { Artigo com maior } \\
\text { quantidade de citações }\end{array}$ \\
\hline Astrofísica & 7 & 21 & 603 \\
\hline Física Teórica & 12 & 6 & 75 \\
\hline Física Experimental & 48 & 12 & 380 \\
\hline
\end{tabular}

Fonte: Elaboração própria a partir da plataforma SOMOS UFMG (2017) e da base Scopus (2017).

O reagrupamento dos dados de produção média e o total de citações recebidas em média por artigo revela uma anticorrelação. Conforme mostrado no Gráfico 7, observa-se que à medida que aumenta o número médio de artigos publicados em cada faixa, reduz-se o 
número de docentes que publicam nessa faixa, mas também é observada uma redução da média de citações que os trabalhos da faixa receberam.

Gráfico 7 - Produção de artigos por faixas de contribuição dos docentes (em \%) e citações médias

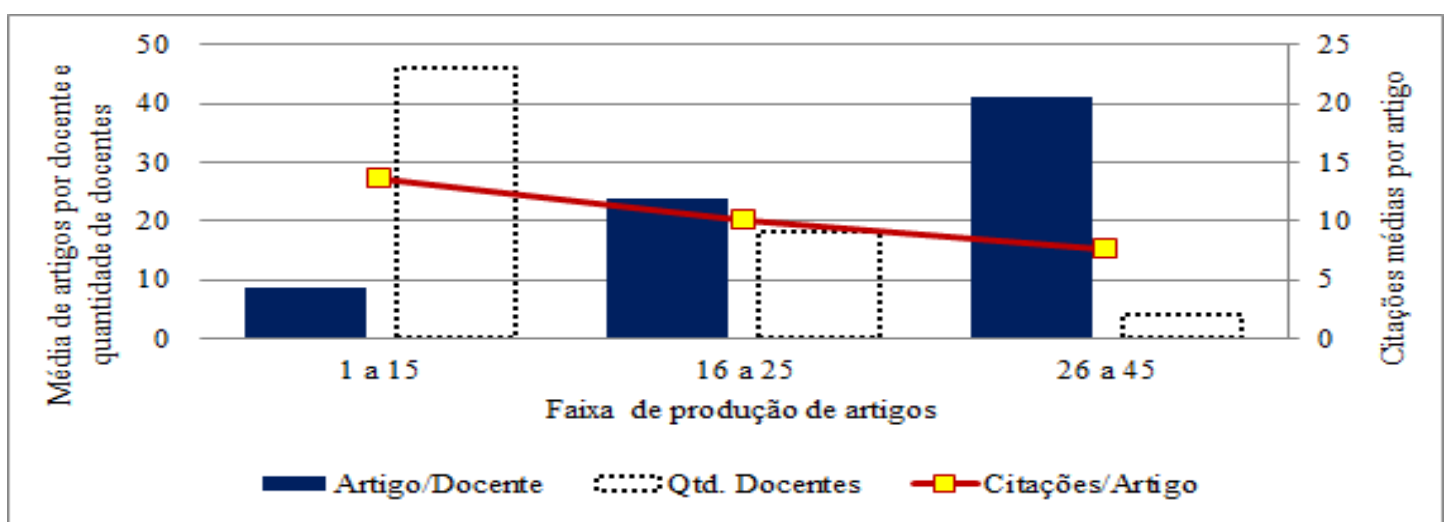

Fonte: Elaboração própria a partir da plataforma SOMOS UFMG (2017) e da base Scopus (2017).

Outro fator analisado quanto a sua influência na produção científica foi o tempo de permanência dos docentes no quadro permanente da UFMG. Uma vez que a média de permanência dos 68 docentes analisado é de 18 anos, realizamos a subdivisão dos docentes em faixas de nove anos para cruzar os dados das médias de artigos por autor e de citações por artigo conforme indicado no Gráfico 8.

Gráfico 8 - Média de artigos produzidos por grupo de diferentes tempos de UFMG e citações médias do grupo

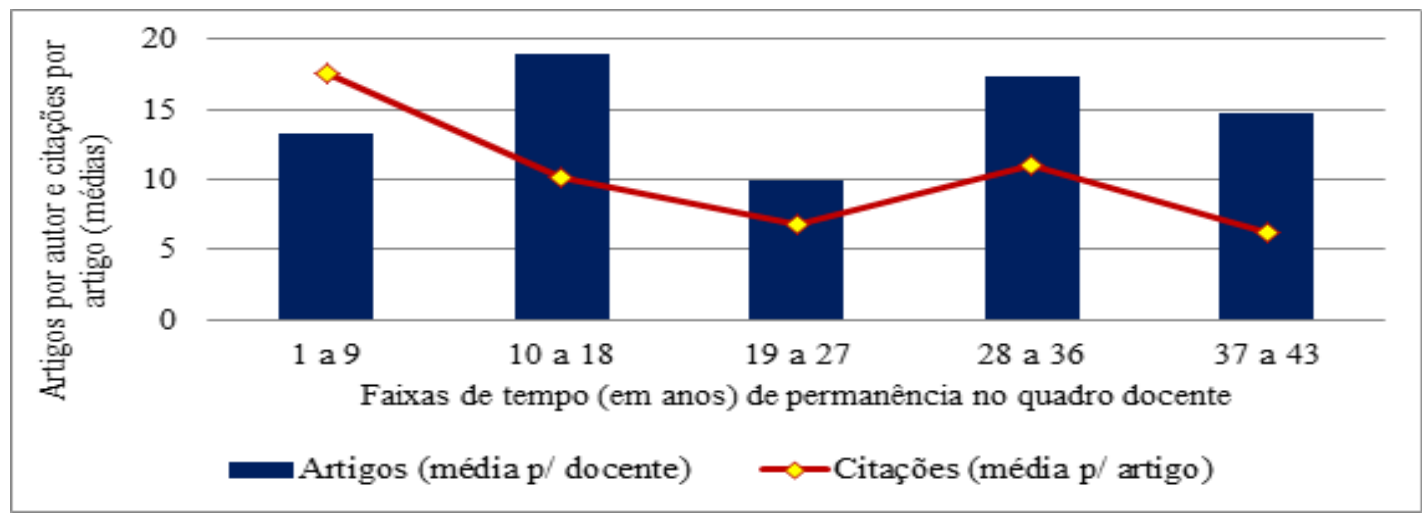

Fonte: Elaboração própria a partir da plataforma SOMOS UFMG (2017) e da base Scopus (2017).

Essa análise revelou que os docentes com menor tempo de UFMG produziram artigos com média maior de impacto em termos de citações $(17,6)$, embora tenham representado a penúltima faixa quanto à produção média de artigos por autor. Os docentes com tempos mais elevados de UFMG apresentaram a menor média de citações $(6,2)$. Cruzando os mesmos dados da análise precedente, mas dividindo os docentes em apenas duas faixas, uma abaixo e outra acima da média de tempo de permanência na UFMG, construímos o Gráfico 9, que nos permite concluir que, de maneira geral, os docentes com menos tempo de atividade na UFMG são mais produtivos e mais citados que os com mais tempo de atividade na UFMG. 
Gráfico 9 - Média de artigos produzidos por grupo de diferentes tempos de UFMG e citações médias do grupo

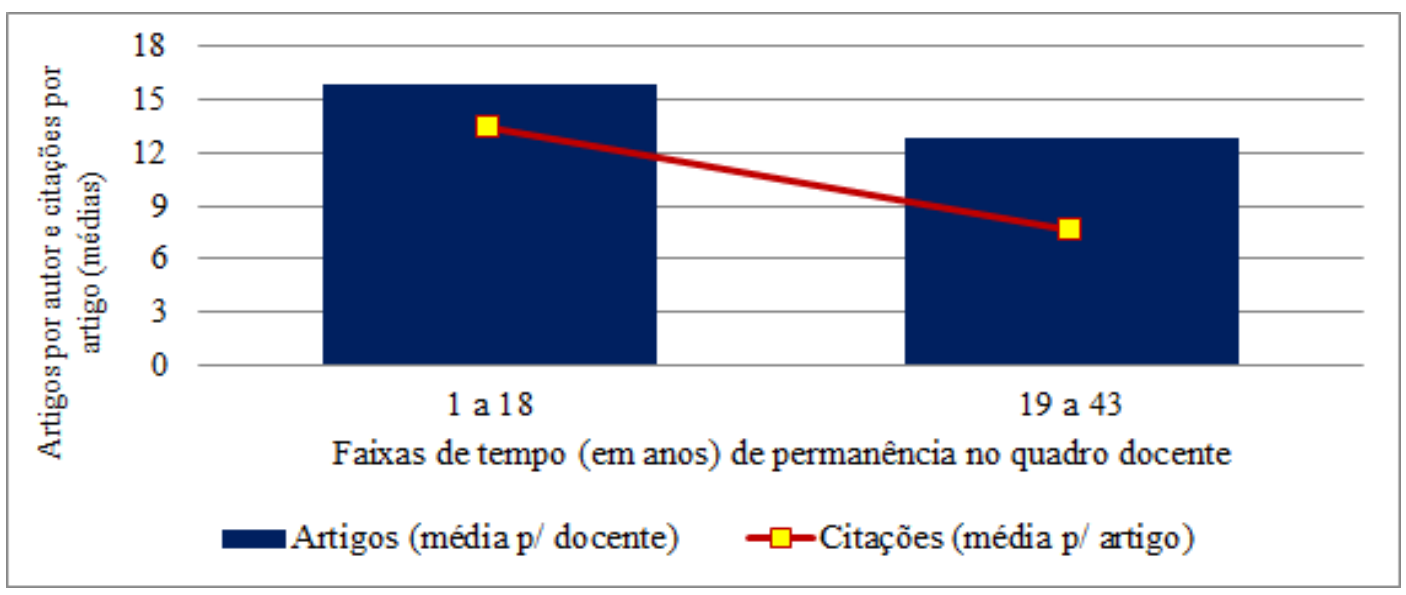

Fonte: Elaboração própria a partir da plataforma SOMOS UFMG (2017) e da base Scopus (2017).

Ao realizarmos análise semelhante à anterior, mas considerando o tempo de obtenção do título de doutor, cuja média geral ficou em 21,4 anos, obtemos o resultado mostrado no Gráfico 10, com faixas de dez em dez anos.

Gráfico 10 - Média de artigos produzidos por grupo de diferentes tempos de doutorado e citações médias do grupo

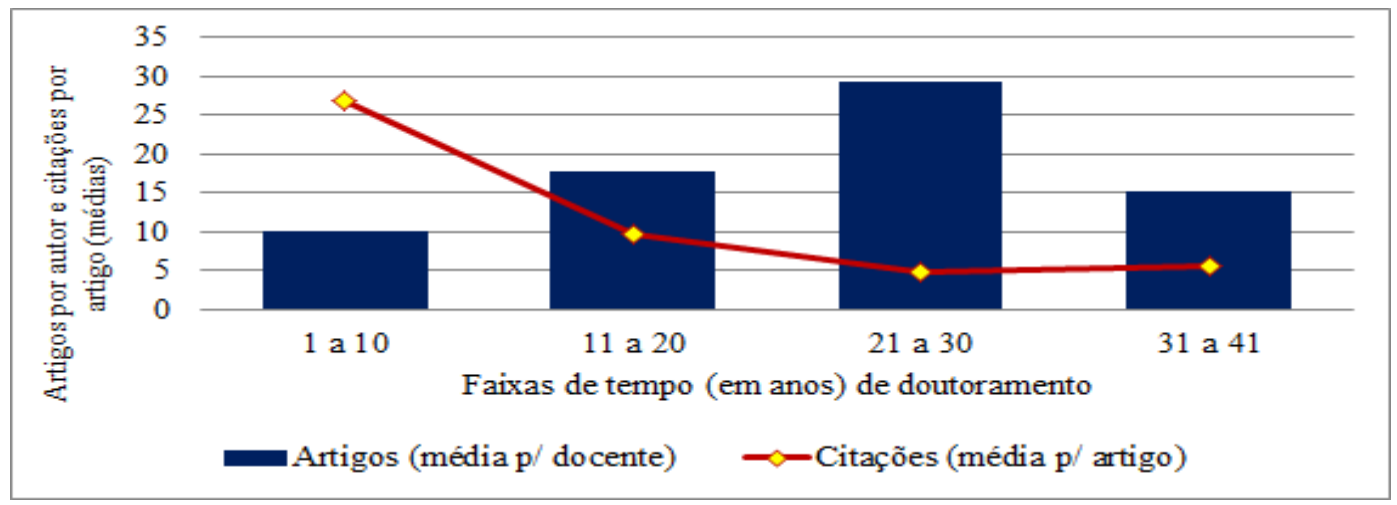

Fonte: Elaboração própria a partir da plataforma SOMOS UFMG (2017) e da base Scopus (2017).

Observa-se que os doutores com até dez anos de titulação apresentaram a menor quantidade média de artigos $(10,1)$, mas com quantidade média de citações por artigo $(26,9)$ muito mais elevada que todas as outras faixas: mais de duas vezes e meia maior que a segunda faixa com mais citações médias - entre 11 e 20 anos com média de 10,3 citações por artigo - e quase cinco vezes maior que a faixa com a menor média de citações por artigo entre 21 e 30 anos com 5,6 citações por artigo. Também é notável observar a relação entre o tempo de doutoramento e a média de citações por artigo: praticamente, à medida que a primeira variável aumentou, a segunda reduziu. Por fim, destaca-se a faixa de 21 a 30 anos de doutoramento, que teve média de 29,4 artigos por docente, mas com a menor quantidade média de citações $(5,0)$. Seguindo a análise por tempo de doutoramento, quando dividimos os docentes em classes abaixo e acima da média de tempo de obtenção do título de doutor, chegamos ao Gráfico 11. 
Gráfico 11 - Média de artigos produzido por grupo de diferentes tempos de doutorado e citação média do grupo

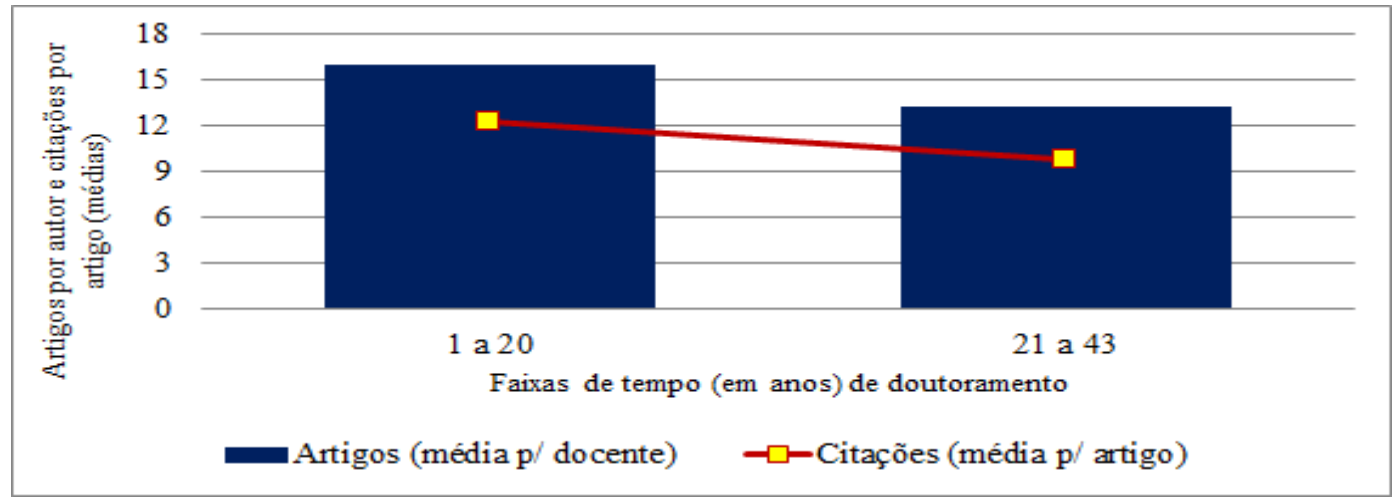

Fonte: Elaboração própria a partir da plataforma SOMOS UFMG (2017) e da base Scopus (2017).

O Gráfico 12 mostra as médias de volume da produção científica e citação por artigo conforme a divisão por sexo. Pode ser observado que a quantidade média de artigos produzidos no período pelas docentes do sexo feminino foi menor, porém, a média de citações desse grupo superou em mais de duas vezes a do grupo masculino.

Gráfico 12 - Média de artigos produzidos por sexo e citação média do grupo

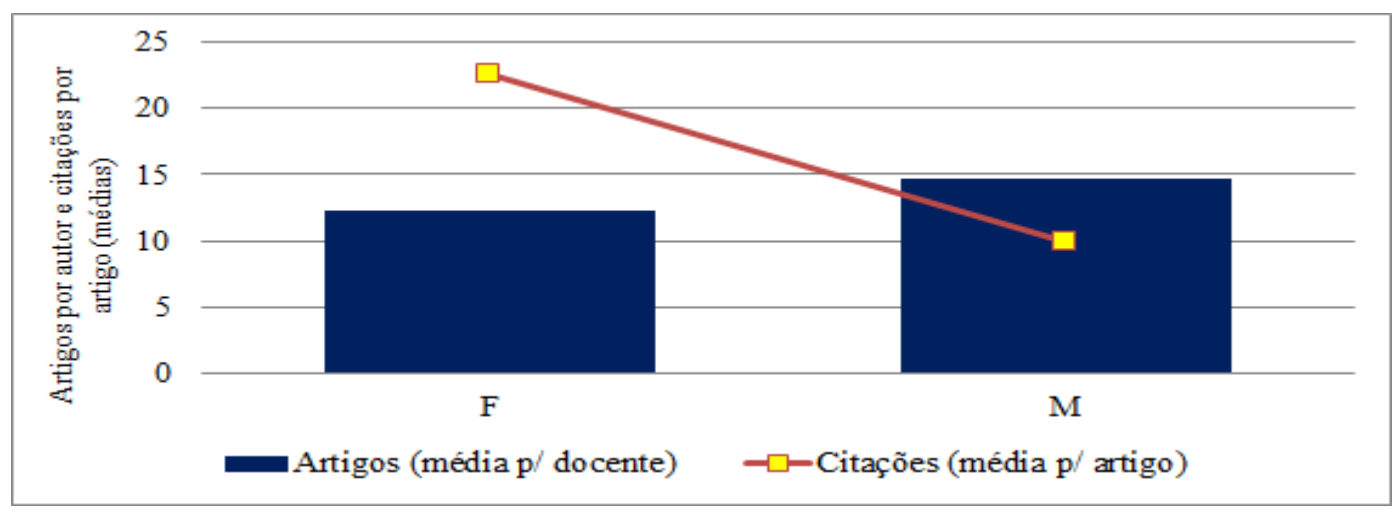

Fonte: Elaboração própria a partir da plataforma SOMOS UFMG (2017) e da base Scopus (2017).

A produção científica da área de Física ocorre com expressiva colaboração entre os pesquisadores. Identificamos nas três últimas análises anteriores, as quais consideraram tempo de permanência na UFMG, tempo de conclusão do doutorado e sexo, que os grupos dos quais os artigos receberam maior média de citações foram aqueles em que quantidade média de autores por artigo foi também maior, como mostrado no Gráfico 13.

No Departamento como um todo, pouco menos de $11 \%$ da produção ocorre com até três autores, sendo irrisória aquela em que a autoria é única. Assim, os artigos produzidos em colaboração por quatro autores ou mais representam significativa maioria, com $89,3 \%$, destacando-se aqueles em colaboração entre quatro e nove autores, os quais representam cerca de $63,5 \%$ dos artigos produzidos. 
Gráfico 13 - Artigos e quantidade de autores por artigo

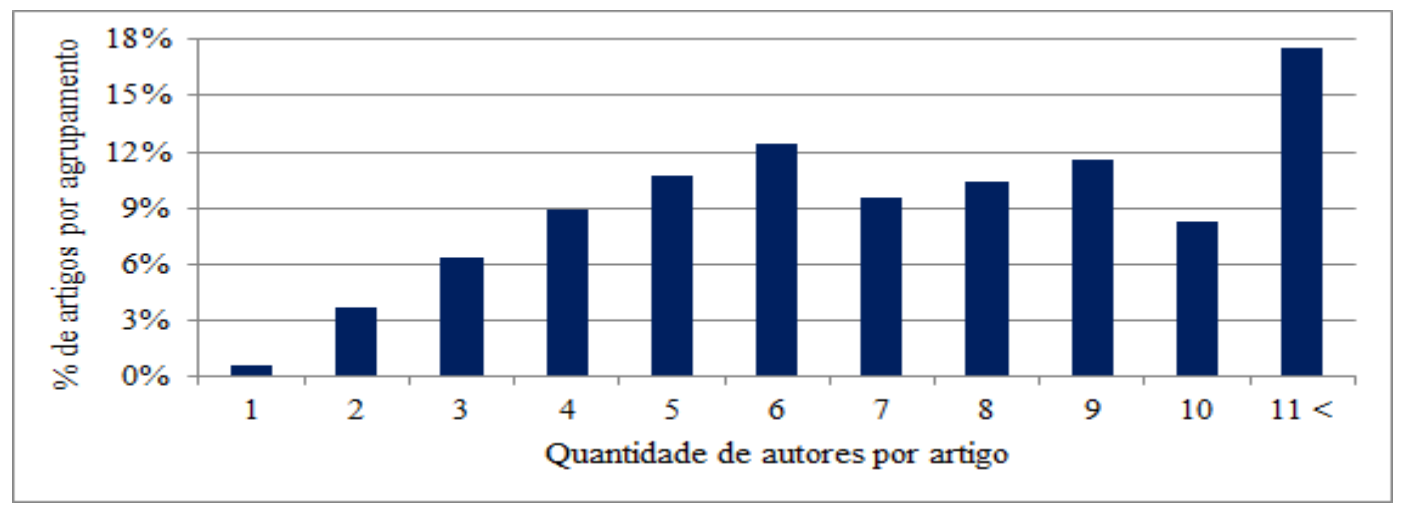

Fonte: Elaboração própria a partir da plataforma SOMOS UFMG (2017) e da base Scopus (2017).

Vale destacar que o artigo publicado no período analisado com a maior quantidade de autores foi escrito por 46 pesquisadores, sendo que o autor do Departamento de Física associado a ele é da área de concentração em Astrofísica. De fato, entre os 15 artigos com maiores quantidades de autores, 12 são da área de Astrofísica. Por outro lado, dos seis artigos de autoria única, cinco são de autores da Física Teórica - o outro é de autor da Astrofísica.

Os dados de coautoria cruzados com média de artigos por docente e citações médias por artigos estão mostrados no Gráfico 14. Eles revelam que, em relação à média de citações por artigo, a Astrofísica apresenta o maior valor, com 21 citações em média por artigo, seguida da Física Experimental, com 11, e o menor valor ficando com a Física Teórica, seis. 0 mesmo ocorre em relação à quantidade média de autores por artigo: 11 em Astrofísica, oito em Física Experimental e cinco em Física Teórica. Observa-se ordem inversa em relação à quantidade média de artigos por docente, em que esta é de dez para a Astrofísica, 15 para a Física Experimental e de 16 para a Física Teórica.

Gráfico 14 - Artigos produzidos por área de concentração, citações por artigo e coautores por artigos - médias

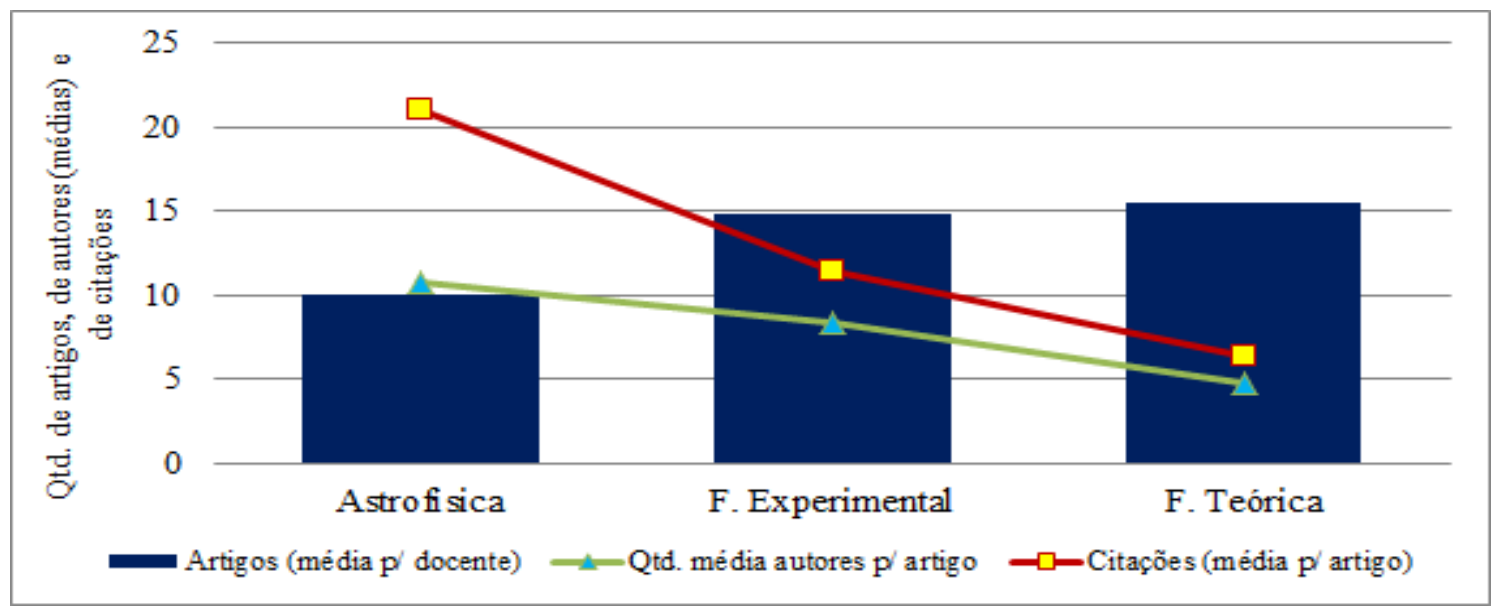

Fonte: Elaboração própria a partir da plataforma SOMOS UFMG (2017) e da base Scopus (2017). 
Se considerarmos o valor médio do impacto dos periódicos em que os artigos foram publicados, medido pelo Simago Journal and Country Rank $(\mathrm{SJR})^{10}$, constatamos que as três áreas de concentração, no período analisado, estão com comportamento "normal" para a média de citações por artigo, uma vez que este valor é de 2,4 para a Astrofísica, 1,8 para a Física Experimental e 1,4 para a Física Teórica. Ou seja, os artigos da área de concentração Astrofísica geralmente recebem em média mais citações que os da Física Experimental, que, por sua vez e também geralmente, recebem mais que os da Física Teórica.

\section{CONCLUSÃO}

Neste trabalho avaliamos parâmetros bibliométricos da produção científica de 68 docentes ativos permanentes do Departamento de Física da UFMG no período compreendido entre 2012 e 2016 - ano de referência 2017. Este estudo revelou uma comunidade científica consolidada, apesar de ser atualmente composta em sua maioria por docentes relativamente jovens em termos de permanência no quadro docente da UFMG. Com média de 18,6 anos, quase todos tendo alcançado a titulação de doutor antes dessa condição profissional, com exceção de nove docentes mais antigos no Departamento. Destaca-se ainda a predominância de docentes vinculados à área de concentração Física Experimental como a que tem mais docentes atuantes: 48 (72\%), ao passo que são 13 (18\%) na Física Teórica e sete (10\%) na Astrofísica. É também na Física Experimental que se encontra o menor tempo médio de permanência na UFMG e de obtenção de doutorado. Em relação à divisão por sexo, predomina o masculino, com praticamente $90 \%$ do total de docentes. A chegada das mulheres também é bem mais recente, pois elas apresentam cerca de sete anos a menos de tempo médio de UFMG, bem como aproximadamente dois anos e meio anos a menos de tempo de obtenção de doutorado. Quanto à endogenia relativa ao local de conclusão do doutorado, para ambos os sexos quase metade teve como orientador alguém do próprio Departamento $-47 \%$.

Em relação à produção científica do período analisado, um olhar panorâmico apresenta os seguintes resultados: 68 docentes publicaram 736 documentos que, considerando as coautorias internas ao Departamento, chega-se a 983 artigos. No entanto, a produção foi decrescente: de 172 artigos em 2012, a série histórica terminou com 137, passando pelo ano de menor produção, o penúltimo, com 127 artigos publicados, 26\% a menos que o ano inicial. Assim, a média de artigos por docente atingiu 14,5, ou 2,9 por ano. As citações dos 715 artigos publicados em periódicos indexados pela Scopus somaram 8.447 , portanto, 11,8 por artigo. Essas médias, entretanto, escondem diferenças marcantes. A começar pela produção de artigos considerada por docente. Dois terços dos docentes (42) publicaram pelo menos dez artigos no período, mas apenas um terço dos docentes (23) publicou uma quantidade acima da média de 14,5 artigos. Apenas quatro docentes (6\%) apresentaram produção entre 36 e 45 artigos no período analisado, com uma média de oito artigos por ano.

A literatura relativa à bibliometria sugere que quanto maior a quantidade de publicações por autor, maior tenderia a ser a média de citações recebidas. Porém, observou-se o contrário no universo consultado: em geral quanto maior a média de artigos por docente, menor a quantidade média de citações. Uma hipótese para este desajuste é a proximidade do período analisado (2012 a 2016) com o momento da elaboração deste trabalho (2017).

${ }^{10}$ https://www.scimagojr.com/.

Ci. Inf. Rev., Maceió, v. 6, n. 2, p. 16-33, maio/ago. 2019 
Alguns aspectos interessantes foram identificados ao se cruzar a quantidade de artigos publicados e as citações médias recebidas. Por exemplo, de um modo geral, os docentes com menor tempo de carreira apresentaram maior quantidade de artigos e maior média de citações recebidas do que aqueles que já estão na Universidade por um tempo acima da média do Departamento. Docentes cujo doutoramento ocorreu há menos anos que a média do Departamento apresentaram maior quantidade média de artigos por autor e maior quantidade média de citações por artigo do que aqueles cujo tempo de doutorado está acima da média. Maiores quantidades de artigos produzidos por estes perfis de docentes podem estar associados às demandas inerentes ao início de carreira, tais como maior cobrança por estarem em estágio probatório ou decorrentes da interação com grupos onde os docentes realizaram seu pós-doutoramento antes de serem admitidos na UFMG. Já quanto à maior quantidade de citações recebidas por seus trabalhos, consideramos a hipótese de estes jovens pesquisadores estarem envolvidos em pesquisas de temas mais em voga atualmente.

Ainda tomando publicações e citações, a análise por sexo mostrou que as mulheres produziram menor quantidade média de artigos, mas seus trabalhos receberam em média mais citações. Porém, consideramos que o fato delas representarem apenas $10 \%$ do total de docentes do Departamento dificulta conclusões quanto à influência do sexo na produção científica.

A coautoria revelou-se um aspecto importante para a publicação de artigos na área de Física, uma vez que praticamente nove em cada dez artigos tinham mais de quatro autores, com destaque para aqueles publicados tendo entre quatro e nove autores, que representaram quase dois terços do total. A colaboração se apresentou especialmente forte na área de concentração de Astrofísica e menos intensa na Física Teórica.

Ademais, a coautoria cruzada com a média de artigos por docente e as citações médias por artigos parece sugerir um tipo de comportamento da produção científica em cada área de concentração da Física. Na área de concentração de Astrofísica cada docente contribuiu individualmente com menor quantidade média de artigos, mas apresentou maior colaboração nesta produção, bem como maior quantidade média de citações recebidas por artigo. Essa mesma relação pode ser observada proporcionalmente nas outras duas áreas de concentração. Em aberto restou identificar se a quantidade média de autores por artigo e de artigos por autor estão em concordância com o comportamento padrão de cada área de concentração, o que poderia ser alcançado a partir de uma comparação com outras instituições.

Seja como for, a relação positiva entre grau de colaboração e citações recebidas parece se confirmar na medida em que também as análises que consideraram tempo de permanência na UFMG, tempo de conclusão do doutorado e sexo, mostraram que os grupos com maior índice de citações foram aqueles com maior quantidade média de autores por artigo, quais sejam: o grupo com menor tempo de permanência na UFMG, ou com menor tempo de conclusão do doutorado e o formado pelas mulheres.

Enfim, embora tenhamos abordado apenas cinco anos de produção científica e a análise possa ter sido prejudicada pela proximidade do período considerado com o momento de elaboração do presente trabalho, acreditamos ter apontado aspectos relevantes da produção científica do Departamento de Física do ICEx da UFMG e esperamos que esses apontamentos possam ser úteis ao desenvolvimento da própria comunidade pesquisada. Finalmente, também indicamos como resultado deste estudo a possibilidade de que sirva para comparações analíticas quando da realização de pesquisas afins em comunidades científicas semelhantes. 


\section{REFERÊNCIAS}

ARAÚJO, C. A. Bibliometria: evolução histórica e questões atuais. Em Questão, Porto Alegre, v. 12, n. 1, p. 11-32, jan./jun. 2006. Disponível em:

https://seer.ufrgs.br/EmQuestao/article/view/16/5. Acesso em: 1 nov. 2017.

BRAMBILLA, S. D. S.; STUMPF, I. R. C. Produção científica da UFRGS representada na Web of Science (2000-2009). Perspectivas em Ciência da Informação, Belo Horizonte, v. 17, n. 3, p. 34-50, set. 2012. Disponível em:

http://portaldeperiodicos.eci.ufmg.br/index.php/pci/article/view/1824/1453. Acesso em: 1 nov. 2017.

BORDONS, M.; ZULUETA M. A. Evaluación de la actividad científica a través de indicadores bibliométricos. Revista Española de Cardiología, Madri, v. 52, n. 10, p. 790-800, out. 1999. Disponível em: https://www.revespcardiol.org/es-pdf-X0300893299001904. Acesso em: 1 nov. 2017.

BRAGA, G. M. Informação, Ciência, Política Científica: o pensamento de Derek de Solla Price. Ciência da Informação, Rio de Janeiro, v. 3, n. 2, p. 155-177, 1974. Disponível em: http://revista.ibict.br/ciinf/article/view/50/50. Acesso em: 1 Nov. 2017.

CORREIA, A. E. G. C.; ALVARENGA, L.; GARCIA, J. C. R. Atividades administrativas e produção científica dos docentes: reflexos em Programas Brasileiros de Pós-Graduação em Física.

Perspectivas em Ciência da Informação, Belo Horizonte, v. 19, n. 3, p. 98-117, jul./set. 2014. Disponível em: http://portaldeperiodicos.eci.ufmg.br/index.php/pci/article/view/1824/1453. Acesso em: 1 nov. 2017.

GUIRADO, J. R. Produção científica da área das Ciências Biológicas da Universidade Federal de Minas Gerais (UFMG) indexada nas bases de dados Web of Science e SCOPUS (2007 2012). 2015. 213 f. Dissertação (Mestrado em Ciência da Informação) - Escola de Ciência da Informação, Universidade Federal de Minas Gerais, Belo Horizonte, 2015. Disponível em: http://www.bibliotecadigital.ufmg.br/dspace/bitstream/handle/1843/BUBD-

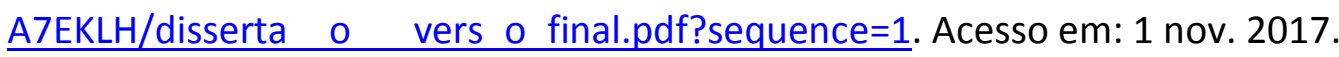

LEITE, C. M. W.; RAMALHO, F. A. Produção científica: um estudo com professores universitários. Biblionline, João Pessoa, v. 1, n. 1, p. 1-13, jan./jun., 2005. Disponível em: http://periodicos.ufpb.br/ojs2/index.php/biblio/article/view/555/399. Acesso em: 1 nov. 2017.

LIMA, M. F. B. F. Produção científica: revisão parcial da literatura brasileira com ênfase na área agrícola. Ciência da Informação, v. 22, n. 3, p. 233-236, 1993. Disponível em: http://revista.ibict.br/ciinf/article/view/482/482. Acesso em: 1 nov. 2017.

MEDEIROS, A. P. S. C; FARIA, L. I. L. Análise bibliométrica da produção científica da UNESP. In: Seminário Nacional de Bibliotecas Universitárias - SNBU, 14., 2006, Salvador, Bahia. Anais [...] Salvador, Bahia: Universidade Federal da Bahia, 2006. Disponível em: 
http://200.136.214.89/nit/refbase/arquivos/faria/541 Faria+Medeiros.pdf. Acesso em: 1 nov. 2017.

MUELLER, S. P. M. Estudos métricos da informação em ciência e tecnologia no Brasil realizados sobre a unidade de análise artigos de periódicos. Liinc em Revista, v. 9, n. 1. p. 6-27, mai. 2013. Disponível em: http://revista.ibict.br/liinc/article/view/3429/2999. Acesso em: 1 nov. 2017.

PERC, M. The Matthew Effect in empirical data. Journal of the Royal Society Interface, n. 11, 2014. Disponível em: https://royalsocietypublishing.org/doi/pdf/10.1098/rsif.2014.0378. Acesso em: 1 nov. 2017.

URBIZAGÁSTEGUI ALVARADO, R. U. A produtividade dos autores na literatura de enfermagem: um modelo de aplicação da Lei de Lotka. Informação \& Sociedade: Estudos, João Pessoa, v. 16, n. 1, p. 83-103. Disponível em:

http://www.ies.ufpb.br/ojs2/index.php/ies/article/view/442/1494. Acesso em: 1 nov. 2017.

VANTI, N. A. P. Da bibliometria à webometria: uma exploração conceitual dos mecanismos utilizados para medir o registro da informação e a difusão do conhecimento. Ciência da Informação, Brasília, v. 31, n. 2, p. 369-379, maio/ago. 2002. Disponível em: http://revista.ibict.br/ciinf/article/view/970/1007. Acesso em: 1 nov. 2017.

VANZ, S. A. S; CAREGNATO, S. E. Estudos de citação: uma ferramenta para entender a comunicação científica. Em Questão, v. 9, n. 2, p. 295-307, jul./dez. 2003. Disponível em: https://seer.ufrgs.br/index.php/EmQuestao/article/viewFile/75/35. Acesso em: 1 nov. 2017. 